\title{
Firm Liability When Third Parties and Consumers Incur Cumulative Harm
}

\author{
Tim Friehe $^{1}$ D $\cdot$ Eric Langlais $^{2} \cdot$ Elisabeth Schulte $^{1}$
}

Accepted: 8 October 2021 / Published online: 30 October 2021

(c) The Author(s) 2021

\begin{abstract}
This paper analyzes liability rules when consumers and third parties/the environment incur harm. Expected harm is convex in the level of output and modeled as a power function. We show that the social ranking of liability rules previously established for the case in which only consumers suffer harm (Strict Liability dominates No Liability and Negligence) may be reversed if harm to third parties or the environment is sufficiently important.
\end{abstract}

Keywords Liability $\cdot$ Cumulative harm $\cdot$ Environmental harm

JEL Classification $\mathrm{K} 13 \cdot \mathrm{Q} 50$

\section{Introduction}

\subsection{Motivation and Main Results}

Product-related accidents may harm consumers as well as third parties/the environment. Third-party effects can result from the widespread usage of the product in a neighborhood, through leakages, emissions, disseminating effects, etc., as well as from accidental events that induce consumers' harm (e.g., via flying debris). Consider, for example, the use of glyphosate by farmers for agricultural weed control. Glyphosate is currently the most

Tim Friehe

tim.friehe@uni-marburg.de

Eric Langlais

eric.langlais@parisnanterre.fr

Elisabeth Schulte

elisabeth.schulte@uni-marburg.de

1 Marburg Centre for Institutional Economics (MACIE), University of Marburg, Marburg, Germany

2 EconomiX UMR 7235 CNRS and Paris Nanterre, 200 Avenue de la Republique, 92001 Nanterre Cedex, France 
widely used herbicide globally and supposedly harms both human health and the environment (Dias et al. 2019). In this context, third-party effects may stem from, for example, exposure from the spraying of fields or water contamination (e.g., Sanchis et al. 2012). ${ }^{1}$ Another example is pharmaceuticals. For example, Heberer (2002) and Li (2014) report that sewage treatment plants incompletely remove pharmaceuticals even in developed countries. Therefore, they are ultimately discharged into the environment. With respect to consumer harm from pharmaceuticals, there exists evidence that increases in acetaminophen usage can raise the probability and extent of liver damage, that increases in the usage of aspirin and other nonsteroidal anti-inflammatory drugs can raise the probability and extent of internal bleeding, and so on (e.g., Daughety and Reinganum 2014). The microplastic used, for instance, in personal care products and clothing represents just another example with potential harm to consumers and third parties/the environment (e.g., Prata et al. 2020). ${ }^{2}$

This paper analyzes liability rules when both consumers and third parties/the environment incur harm. Previous analyses of firm liability assume that either consumers or third parties suffer harm. In our framework, when considering how different liability regimes influence privately optimal care and output choices by a monopolistic firm, we consider a weighting scheme that allows us to express the importance of consumer harm relative to third-party harm. We analyze a model in which the harm develops as a strictly convex function in the product's quantity, an important and realistic assumption. For example, the environmental harm from antibiotics in the groundwater will presumably be non-linear (e.g., Martinez 2009). More generally, given that the environment is a complex system potentially involving tipping points (e.g., Mäler et al. 2003), disproportionally increasing environmental harm appears very reasonable. To focus on the role of the simultaneous presence of consumer and third party harm and follow previous literature on environmental liability law (e.g., Van Egteren and Smith 2002), we use a simplistic representation of the compensation for environmental harm, for example, by abstracting from measurement issues and the distinction between the level of harm on the one hand and the level of cleanup costs on the other. ${ }^{3}$

Liability rules are an important instrument in the policymaker's toolbox (e.g., Van Egteren and Smith 2002; Endres 2011). The determination of liability for harm in tort cases is based on two main liability schemes: either Strict Liability or Negligence. Strict Liability means that an injurer is liable regardless of how the activity that caused the harm was undertaken. Meanwhile, under Negligence, liability is contingent on the producers' actions. In real-world legislation, it often depends on the activity, whether Strict Liability or Negligence applies. For instance, the Environmental Liability Directive of the European Union lists activities that are subject to Strict Liability, while other activities are subject to Negligence. Much of the literature about liability rules is devoted to delineating under which circumstances one liability rule outperforms the other (e.g., Shavell 2007).

\footnotetext{
1 See, for example, Dias et al. (2019) for a study of the potential effects on birth outcomes.

2 Examples where products may cause harm to consumers and other people (as third parties) include smoke from tobacco products, potentially exploding smartphones (Samsung Galaxy Note 7), and soft drinks in bottles (e.g., Escola v. Coca-Cola Bottling Co., 150 P.2d 436, 24 Cal. 2d 453, 1944)).

3 In contrast, Endres and Friehe (2015) focus on the role of the compensation regime in environmental liability law, distinguishing the cases (1) compensation for the level of harm, (2) compensation for clean-up costs, and (3) compensation for a combination of the level of harm and the level of clean-up costs.
} 
We find that the explicit consideration of harm to third parties or the environment is consequential to the relative performance of liability rules. Our results show that the ranking of liability rules previously established by Daughety and Reinganum (2014) for the case in which only consumers suffer harm-Strict Liability dominates No Liability and Negligence - may be reversed in our setting. First, we show that No Liability can, in specific circumstances, produce the outcome that occurs under Strict Liability. To obtain this finding in our framework, harm to consumers must stand in a specific relationship to third-party or environmental harm (in a way made more precise below). Relative to Strict Liability, No Liability implies two effects, which perfectly offset each other when the relative importance of second-party harm to third-party harm is of a well-defined magnitude. Within limited parameter bounds, No Liability outperforms Strict Liability because it can induce greater output. Second, and perhaps more importantly, we delineate circumstances in which Negligence yields higher welfare than Strict Liability. For Negligence to possibly dominate Strict Liability, third-party harm must be sufficiently important relative to consumer harm (in a way made more precise below). In these circumstances, the firm strictly prefers being not liable to being liable, and the social planner can utilize this firm preference to implement a socially preferred social outcome. More specifically, the firm's strict preference for being not liable creates a willingness to pay in terms of greater product safety on behalf of the firm, and the social planner can exploit this fact to achieve higher welfare. In two extensions of our model, we briefly consider the case where the liability regime for consumer harm may differ from that concerning environmental harm and comment on the role of regulation in our framework.

\subsection{Related Literature}

Our paper considers liability regimes when both consumers and third parties incur cumulative harm. There is a vast literature on product liability (see, e.g., the surveys by Daughety and Reinganum 2013b, and Geistfeld 2009). The traditional setup assumes perfectly competitive firms, identical risk-neutral consumers, common knowledge about expected harm, costless trials, and that both care costs and expected harm are proportional to output. The traditional framework delivers the key finding that Strict Liability, Negligence, and No Liability are all equally efficient when consumers are perfectly informed about care and do not misperceive risk (e.g., Shavell 1980). The rationale is that the firm cares about expected harm because the latter affects the consumers' willingness to pay when it would otherwise be missing from the firm's profit maximization. In that standard framework, when third parties incur harm instead of consumers, Strict Liability and Negligence are equally efficient, whereas No Liability produces an inefficient outcome (so that we have a standard "negative externality" problem; see, e.g., Shavell 1987).

The irrelevance result for the scenario in which only consumers are harmed depends on the traditional setup's far-reaching assumptions. The importance of these assumptions is well-documented in the literature. For example, Daughety and Reinganum (2006) consider a scenario in which product safety is chosen in a preliminary R\&D stage and implies a fixed cost, introducing a strategic "business-stealing" effect of product safety. Other examples of departures from the standard framework include Daughety and Reinganum (1995), who analyze product liability when the level of product safety is the firm's private information, and Friehe et al. (2018), who focus on the influence of litigation costs and the implication of a probability of suit strictly below one. We will abstract from all of these 
complications and instead focus on the implications from a novel specification of expected harm that includes harm to consumers and third parties/the environment.

In the previous literature, firm liability for harm to third parties or the environment is separated from the liability of firms for harm to consumers. The former has been studied in relation to various issues, including liability sharing (Hansen and Thomas 1999; Watabe 1999), or extended liability and the judgment proof problem (Boyer and Laffont 1997, Evans and Gilpatric 2017); other work has focused on the incentives to adopt green innovations (Endres and Friehe 2011; Endres et al. 2007), or the interplay with competitive distortions (Charreire and Langlais 2021).

For our analysis and results, it is important that we consider cumulative harm, thereby building on Marino (1988) and Daughety and Reinganum (2013, 2014). Our contribution to this branch of literature considers the scenario in which harm is incurred not only by consumers but also third parties/the environment. This is particularly interesting because the driving force in this context, namely that the marginal expected harm exceeds the average expected harm per unit of output, is only relevant to the extent that it affects consumers, but not third parties.

Hay and Spier (2005) consider a model in which the products that consumers purchase from firms may cause harm to third parties, where the expected harm is influenced by product safety and consumer care. A realistic case-in-point for a product in their setup is guns. The authors show that full consumer liability induces the first-best outcome in a benchmark model, but also that shifting liability from the consumer to the firm may be desirable in some circumstances (e.g., when the consumer is potentially judgment-proof, that is, unable to pay the compensation due in the event of an accident). In contrast, we focus on the firm's efforts to address expected harm and include circumstances in which the harm to third parties is not caused by consumers. Suppose, for example, that a manufacturer produces output using chemicals, where the types and volume of chemicals influence the expected harm to consumers (e.g., toxic chemicals in apparel) and the environment (e.g., from planned or accidental emissions during the production process).

\subsection{Plan of the Paper}

In Sect. 2, we present the framework used for our analysis. In Sect. 3, we first describe and compare the firm's decision-making under Strict Liability and No Liability in terms of welfare. Next, we analyze how the firm behaves when it is subject to Negligence and address the relative performance of Negligence. We conclude in Sect. 4.

\section{Model}

Our model builds on Daughety and Reinganum (2014), who use a representative consumer framework. Specifically, we consider a risk-neutral monopolist serving a market described by a linear (inverted) market demand gross of any harm $P(q)=a-b q$, where $q$ denotes output, and $a$ and $b$ are positive parameters. This (inverted) demand results from maximizing a quasi-linear utility gross of any harm, $U=a q-b q^{2} / 2+r$, subject to the budget constraint, $y=r+P q$ where $r$ represents a numeraire good and $y$ exogenous income. The firm incurs a cost $C(q, x)=c(x) q$, where $x$ denotes product safety and $c^{\prime}(0)=0=c(0), c^{\prime}>0$, and $c^{\prime \prime}>0$ for all $x>0$. To provide an analysis focused on incorporating third-party harm, we abstract from the possibility that liability induces firm insolvency. 
Observable product safety influences the expected harm caused to the representative consumer and/or a third party. Similar to Daughety and Reinganum (2014), we assume that the total expected harm can be described by the strictly convex function $H(q, x)=\gamma h(x) q^{\theta}$, where $\theta>1, h(0)>0$ and, for any $x, h^{\prime}(x)<0<h^{\prime \prime}(x)$. Importantly, we assume that $\gamma=\alpha+\beta$ so that $\alpha h(x) q^{\theta}$ measures consumer harm and $\beta h(x) q^{\theta}$ represents third-party/environmental harm. ${ }^{4}$ We consider $\alpha$ and $\beta$ to be non-negative scalars and, below, will refer to the polar cases in which harm is incurred either only by consumers or by the environment (i.e., the scenario in which either $\alpha>0=\beta$ or $\alpha=0<\beta$ holds). When we fix the parameter values to $\theta=2, \alpha=1$, and $\beta=0$, we obtain the framework used by Daughety and Reinganum (2014). Needless to say, our assumptions about how expected harm depends on firm output and how it can be separated into consumer and third-party harm will imprint on the exact results presented below.

The timing is such that, in Stage 1, the firm determines the level of observable product safety and the level of output in view of the consumer's decision-making in Stage 2, as represented by the market demand function. In Stage 3, after an accident, the firm is made to compensate for any harm when judged liable in (socially and privately) costless litigation.

\section{Analysis}

In Sects. 3.1 and 3.2, we will describe market outcomes when the firm faces No Liability or is subject to Strict Liability. In Sect. 3.3, we compare the privately optimal choices under the respective regimes from a welfare perspective. Section 3.4 continues with an analysis of firm behavior under Negligence with a well-defined product safety standard and how welfare under Negligence compares to that under other liability rules. ${ }^{5}$ A brief discussion of possible model extensions concludes Sect. 3 .

Before we start our analysis of decentralized decision-making, we note that the socially optimal levels of output and safety, $\left\{\hat{q}^{W}, \hat{x}^{W}\right\}$, maximize

$$
W(q, x)=\left(a-\frac{b}{2} q-c(x)\right) q-\gamma h(x) q^{\theta}
$$

and are characterized by the first-order conditions for an interior solution ${ }^{6}$

$$
\begin{gathered}
W_{q}=a-b q-c(x)-\gamma \theta h(x) q^{\theta-1}=0 \\
W_{x}=-c^{\prime}(x) q-h^{\prime}(x) \gamma q^{\theta}=0,
\end{gathered}
$$

where we use subscripts to denote partial derivatives. We denote with $q^{W}(x)$ the function that yields the first-best output for the given product safety level, derived from condition

\footnotetext{
${ }^{4}$ We abstain from incorporating mitigation incentives discussed in Endres and Friehe (2015) and Friehe and Langlais (2017), for example.

${ }^{5}$ The close analogy of No Liability and Strict Liability, when compared to Negligence, justifies this sequence. Note that we assume throughout that firms are legally constrained by the respective regime, that is, cannot contractually circumvent it using a voluntary offer to compensate consumers' losses, for example (as in, e.g., Chen and Hua 2017). For contributions focusing on contractual liability, refer to Arlen (2010), Choi and Spier (2014), and Wickelgren (2006), for example.

${ }^{6}$ See Appendix A for the description of sufficient conditions.
} 
(2). Similarly, the function that yields the first-best product safety level for a given output level is denoted $x^{W}(q)$ and results from condition (3). The socially optimal levels of output and product safety result to

$$
\left\{\hat{q}^{W}, \hat{x}^{W}\right\}=\left\{q^{W}\left(\hat{x}^{W}\right), x^{W}\left(\hat{q}^{W}\right)\right\}
$$

\subsection{Care and Output Under No Liability}

Under No Liability, total harm remains with the consumer and/or the third party. This influences the consumer's willingness to pay derived in Stage 2. Considering the marginal effects flowing from the maximization of $\tilde{U}=a q-b q^{2} / 2+y-P q-\alpha h(x) q^{\theta}$, that is, expected payoffs accounting for the budget constraint and expected harm, we can assert that

$$
P(q)=a-b q-\alpha \theta h(x) q^{\theta-1}
$$

is the relevant (inverted) market demand for the firm to consider in the first stage.

In Stage 1, the monopolist chooses output and product safety in order to maximize

$$
\Pi^{N L}(q, x)=(a-b q-c(x)) q-\alpha \theta h(x) q^{\theta} .
$$

The privately optimal level of product safety conditional on output, $x^{N L}(q)$, and the privately optimal level of output conditional on product safety, $q^{N L}(x)$, satisfy

$$
\begin{gathered}
\Pi_{q}^{N L}=a-2 b q-c(x)-\alpha \theta^{2} h(x) q^{\theta-1}=0 \\
\Pi_{x}^{N L}=-c^{\prime}(x) q-h^{\prime}(x) \alpha \theta q^{\theta}=0 .
\end{gathered}
$$

The profit-maximizing levels of output and product safety result to

$$
\left\{\hat{q}^{N L}, \hat{x}^{N L}\right\}=\left\{q^{N L}\left(\hat{x}^{N L}\right), x^{N L}\left(\hat{q}^{N L}\right)\right\} .
$$

As is clear from the last term in condition (5), the firm internalizes the marginal output costs to the extent that the higher expected harm reduces the consumer's willingness to pay, $\alpha \theta^{2} h(x) q^{\theta-1}$. In contrast, marginal expected social harm amounts to $\gamma \theta h(x) q^{\theta-1}$. Under No Liability, the firm is only concerned about harm incurred by the consumer and not about harm incurred by the third party/the environment, suggesting that output under No Liability will be excessive. However, it is important to note that the firm internalizes how its output increase changes the consumer's marginal harm instead of how its output variation influences the consumer's average harm, making inefficiently low output possible under No Liability. Similarly, with respect to product safety, the information about the marginal benefit from product safety is transmitted to the firm via the change in the consumer's willingness to pay which only reflects the repercussions for the consumer's marginal harm.

It is instructive to consider the problems associated with No Liability in the two polar cases in which harm is incurred either only by consumers or only by the environment. Our analysis of scenarios that lie between these extreme cases means that the respective distortions are counterbalancing each other depending upon the relative importance of consumer harm. 
Remark 1 Assume No Liability. (a) If only consumers incur harm (i.e., if $\alpha>0=\beta$ ), then (i) output is suboptimal because of the firm's monopoly power and because the firm considers the marginal instead of average harm, and (ii) product safety is excessive because the firm considers the marginal instead of average harm. (b) If only the environment incurs harm (i.e., if $\alpha=0<\beta$ ), then (i) output cannot generally be ranked to $q^{W}(x)$ because monopoly power lowers private output incentives but the firm' failure to internalize the additional harm created increases them, and (ii) product safety is suboptimal because the firm fails to internalize the additional harm created.

\subsection{Care and Output Under Strict Liability}

Under Strict Liability, total harm is shifted from both the consumer and the third party to the firm. Since we assume full compensation of harm, the consumer's willingness to pay derived in Stage 2 does not depend on product safety and can be stated as

$$
P(q)=a-b q .
$$

In Stage 1, the monopolist chooses output and product safety in order to maximize

$$
\Pi^{S L}(q, x)=(a-b q-c(x)) q-\gamma h(x) q^{\theta} .
$$

The firm bears the average of the total expected harm per unit of output. This contrasts with No Liability in two ways. First, the consumer's expected harm enters the firm's maximization problem as the average consumer harm per unit of output. Second, under Strict Liability, the firm internalizes not only consumer harm but also third-party harm.

The first-order conditions are solved by the privately optimal level of product safety conditional on output, $x^{S L}(q)$, and the privately optimal level of output conditional on product safety, $q^{S L}(x)$ when the firm is strictly liable:

$$
\begin{gathered}
\Pi_{q}^{S L}=a-2 b q-c(x)-\gamma \theta h(x) q^{\theta-1}=0 \\
\Pi_{x}^{S L}=-c^{\prime}(x) q-h^{\prime}(x) \gamma q^{\theta}=0
\end{gathered}
$$

The profit-maximizing levels result to

$$
\left\{\hat{q}^{S L}, \hat{x}^{S L}\right\}=\left\{q^{S L}\left(\hat{x}^{S L}\right), x^{S L}\left(\hat{q}^{S L}\right)\right\} .
$$

The per-unit marginal expected liability cost that the firm takes into account is equal to the marginal expected social harm. However, the marginal private benefits of output fall short of the marginal social benefit, signifying that the privately optimal output will tend to be inefficiently low. It results from our assumptions about both the level of compensation being equal to the level of harm and free litigation-which basically means that the firm internalizes the full expected social harm-that Strict Liability induces socially adequate product safety for the given level of output.

Before we enter the comparison of Strict Liability and No Liability, we once again present results for the two polar cases $\alpha>0=\beta$ and $\alpha=0<\beta$.

Remark 2 Assume Strict Liability. For both polar cases (i.e., $\alpha>0=\beta$ and $\alpha=0<\beta$ ), (i) output is suboptimal because of the firm's monopoly power, and (ii) product safety is socially optimal for a given level of output as $x^{W}(q)=x^{S L}(q)$. 


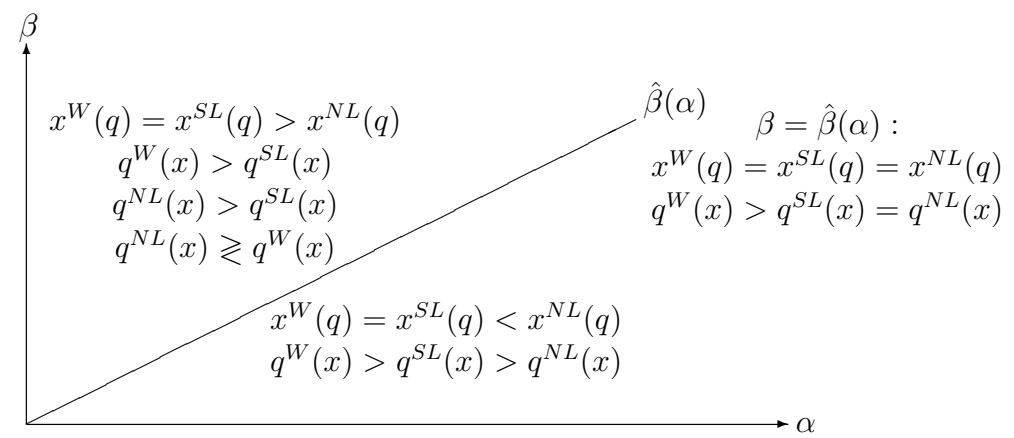

Fig. 1 Comparison of output and safety levels under No Liability (superscript $N L$ ), Strict Liability $(S L)$ and in the first best $(W)$

\subsection{Comparing No Liability to Strict Liability}

While Strict Liability induces the firm to account for the socially adequate marginal expected harm from greater output and the correct marginal benefits from greater product safety for the given output, the monopolistic firm's output is too small. Under No Liability, the marginal effects that the firm internalizes usually differ from their social counterparts. Because the firm creates artificial scarcity to raise the product's price in both regimes, it is unclear whether Strict Liability outperforms No Liability in terms of welfare.

In order to determine whether No Liability or Strict Liability yields greater welfare, we state firm profits as

$$
\Pi(q, x)=(a-b q-c(x)) q-\alpha \kappa h(x) q^{\theta},
$$

with the first-order conditions

$$
\begin{gathered}
\Pi_{q}(q, x)=a-2 b q-c(x)-\alpha \kappa \theta h(x) q^{\theta-1}=0 \\
\Pi_{x}(q, x)=-c^{\prime}(x) q-\alpha \kappa h^{\prime}(x) q^{\theta}=0 .
\end{gathered}
$$

where $\kappa^{S L}=1+\beta / \alpha$ when the firm is subject to Strict Liability and $\kappa^{N L}=\theta$ when No Liability applies. Both regimes produce exactly the same incentives when $\kappa^{N L}=\kappa^{S L}$, that is, when $1+\beta / \alpha=\theta$ holds. This equality results if

$$
\beta=\hat{\beta}(\alpha) \equiv(\theta-1) \alpha,
$$

where $\hat{\beta} \leq \alpha$ if $\theta \leq 2$ and $\hat{\beta}>\alpha$ otherwise. ${ }^{7}$ This means that for any $\alpha$ (i.e., consumer harm), there exists a level of $\beta$ (i.e., third-party harm) such that the institutional choice between Strict Liability and No Liability is irrelevant. This produces a stark contrast to the analysis by Daughety and Reinganum (2014). Whereas the firm under No Liability considers terms including $\alpha \theta$ when assessing output and safety, the firm under Strict Liability considers the same terms with $\gamma$ substituting the $\alpha \theta$. Given any parameter combination

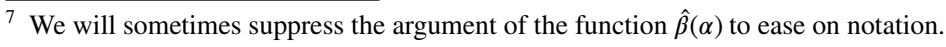


$(\alpha, \beta)$ in our framework, the firm under No Liability will thus consider harm implications from its output and safety choices that are too small (large) relative to the true expected social harm implications when $\beta>(<) \hat{\beta}$. We summarize in Fig. 1 and the next result.

Lemma 1 (i) If $\beta=\hat{\beta}$, the conditional product safety under No Liability is equal to the one under Strict Liability, and both concur with the socially optimal level (i.e., $\left.x^{N L}(q)=x^{S L}(q)=x^{W}(q)\right)$. The profit-maximizing conditional output levels under No Liability and Strict Liability are equal but fall short of the socially optimal one (i.e., $q^{N L}(x)=q^{S L}(x)<q^{W}(x)$ ). (ii) If $\beta<\hat{\beta}$, the conditional product safety level under Strict Liability is equal to the socially optimal one and short of that under No Liability (i.e., $\left.x^{S L}(q)=x^{W}(q)<x^{N L}(q)\right)$. Socially optimal conditional output exceeds output under Strict Liability, which in turn exceeds output under No Liability (i.e., $q^{N L}(x)<q^{S L}(x)<q^{W}(x)$ ). (iii) If $\beta>\hat{\beta}$, the conditional product safety level under Strict Liability is equal to the socially optimal one and in excess of that under No Liability (i.e., $x^{N L}(q)<x^{S L}(q)=x^{W}(q)$ ). In terms of conditional output, the socially optimal level exceeds the privately optimal level under Strict Liability, which is also smaller than output under No Liability (i.e., $q^{S L}(x)<q^{W}(x)$ and $\left.q^{S L}(x)<q^{N L}(x)\right)$.

Proof See Appendix B for the derivation of this result.

Because Strict Liability induces socially optimal product safety conditional on output, No Liability may yield higher welfare only if it produces a socially more desirable output level than Strict Liability. Lemma 1(iii) states that the firm produces more output under No Liability than under Strict Liability when environmental harm is relatively important as the firm fails to internalize environmental consequences of its activity. Starting at $\beta=\hat{\beta}$ where both regimes produce equal welfare, an increase in $\beta$ such that $\kappa^{S L}>\kappa^{N L}$ means that the firm subject to No Liability considers harm consequences short of the social ones and thus will implement a larger level of output and a smaller level of safety when compared to what is obtained when the firm is subject to Strict Liability. When $\beta$ is similar to $\hat{\beta}$, the deviation in terms of product safety will be marginal, but the improvement in terms of output will be discrete. In contrast, a decrease in $\beta$ starting at $\hat{\beta}$ such that $\kappa^{S L}<\kappa^{N L}$ means that the firm subject to No Liability considers harm consequences greater than the social ones and thus will implement a smaller level of output and a higher level of safety when compared to what is obtained under Strict Liability. As a result, Strict Liability produces a welfare level closer to the welfare maximum.

Proposition 1 (i) Strict Liability and No Liability produce the same welfare when $\beta=\hat{\beta}(\alpha)$. (ii) Strict Liability is welfare superior to No Liability when $\beta<\hat{\beta}(\alpha)$. (iii) No Liability is welfare superior to Strict Liability when $\beta$ is greater but close to $\hat{\beta}(\alpha)$, whereas the welfare comparison is ambiguous when $\beta$ is much larger than $\hat{\beta}(\alpha)$.

Proof Part (i) results directly from Lemma 1(i). With respect to parts (ii) and (iii), consider how social welfare changes with the level of $\kappa$ for a fixed combination of $(\alpha, \beta)$ by using how both the output and the product safety level respond to a change in $\kappa$. We derive 


$$
\widetilde{W}(\kappa)=\left(a-\frac{b}{2} q(\kappa)-c(x(\kappa))\right) q(\kappa)-\gamma h(x(\kappa)) q(\kappa)^{\theta}
$$

with respect to $\kappa$ to obtain the marginal welfare effect from a change in the firm's internalization of social marginal effects,

$$
\frac{d \widetilde{W}}{d \kappa}=\left(a-b q(\kappa)-c(x(\kappa))-\gamma \theta h(x(\kappa)) q(\kappa)^{\theta-1}\right) \frac{d q}{d \kappa}+\left(-c^{\prime}(x) q-h^{\prime}(x) \gamma q^{\theta}\right) \frac{d x}{d \kappa} .
$$

After using the first-order conditions (11) and (12), we can state

$$
\frac{d \widetilde{W}}{d \kappa}=\left(b q(\kappa)+\alpha\left(\kappa-\kappa^{S L}\right) \theta h(x(\kappa)) q(\kappa)^{\theta-1}\right) \frac{d q}{d \kappa}+\left(\alpha\left(\kappa-\kappa^{S L}\right) h^{\prime}(x) \gamma q^{\theta}\right) \frac{d x}{d \kappa},
$$

where $d q / d \kappa<0$ and $d x / d \kappa>0$ (see the proof in Appendix B). When $\beta=\hat{\beta}$, the level of $\kappa$ is equal to $\kappa^{S L}$ in both liability regimes. In this circumstance, the derivative of welfare with respect to $\kappa$ is clearly negative. This indicates that a marginally smaller $\kappa$ is welfareimproving as it raises the firm's level of output. When the true $\beta$ is smaller (larger) than $\hat{\beta}$, we have $\kappa^{N L}>(<) \kappa^{S L}$. This finding means that $\beta>\hat{\beta}$ but a value around $\hat{\beta}$ represents a scenario where No Liability can outperform Strict Liability as it induces the smaller level of $\kappa$ for the fixed combination of $(\alpha, \beta)$. This dominance results from the fact that the welfare effect of greater output is first order while the product safety effect is not. When $\beta$ is no longer close to $\hat{\beta}$, the relatively greater output under No Liability is associated with a product safety that is noticeably smaller than that under Strict Liability. This is discussed in claim (iii). In contrast, if $\beta<\hat{\beta}$, Strict Liability induces the socially preferable outcome in terms of both product safety and output.

The two liability regimes can also be compared from the firm's standpoint. This comparison is an important input for the analysis of Negligence conducted in the next section. We find that there are circumstances in which the firm prefers Strict Liability over No Liability and vice versa.

Lemma 2 If $\beta<\hat{\beta}(\alpha)$, the firm's profits are higher under Strict Liability than under No Liability. If $\beta>\hat{\beta}(\alpha)$, the firm earns higher profits under No Liability than under Strict Liability.

Proof By application of the envelope theorem, only the direct effect of $\kappa$ matters such that the firm prefers the regime that yields the smaller level of $\kappa$ as

$$
\frac{d \Pi}{d \kappa}=-\alpha h(x) q^{\theta}<0 .
$$

As a result, the firm prefers No Liability over Strict Liability when $\beta>\hat{\beta}$ and vice versa.

\subsection{Care and Output under Negligence}

Under Negligence, the firm avoids liability by complying with a due safety level. Thus, Negligence allows the firm to choose between the two previously discussed regimes: the 
firm is strictly liable when it chooses product safety below the due level $\bar{x}$, and the firm has payoffs identical to those under No Liability provided that product safety is weakly in excess of the product safety standard. Formally, this means that

$$
\Pi^{N}(q, x)=\mathbf{1}_{\{x \geq \bar{x}\}} \Pi^{N L}(q, x)+\left(1-\mathbf{1}_{\{x \geq \bar{x}\}}\right) \Pi^{S L}(q, x),
$$

with $\mathbf{1}_{\{x \geq \bar{x}\}}$ as an indicator variable equal to one if product safety is at least as high as the standard and zero otherwise.

According to Proposition 1(i) in conjunction with Lemma 2, if $\beta<\hat{\beta}(\alpha)$, Strict Liability is the preferable regime from the firm's point of view and from a welfare perspective. Any due level for product safety in a negligence regime can at best lead to the same level of welfare as under Strict Liability. The firm will certainly not comply with a due level of product safety that is excessive from the firm's point of view. Thus, the firm's decisions cannot be steered in a welfare-improving direction by implementing Negligence instead of Strict Liability. In contrast, if $\beta>\hat{\beta}(\alpha)$, the firm prefers to operate in a regime with No Liability instead of Strict Liability. In particular,

$$
\Pi^{S L}\left(q^{S L}, x^{S L}\right)<\Pi^{N L}\left(q^{S L}, x^{S L}\right)<\Pi^{N L}\left(q^{N L}\left(x^{S L}\right), x^{S L}\right),
$$

such that in a negligence regime with a due level of product safety $\bar{x}=x^{S L}$, the firm will voluntarily comply with the safety standard in order to avoid liability.

Under No Liability, the firm will provide higher output than under Strict Liability if the product safety standard is set at $\hat{x}^{S L}$ (i.e., the profit-maximizing level under Strict Liability). This increase in output is principally socially desirable because the output obtained under Strict Liability is too low from a social perspective. More generally, the firm will comply with a due level of product safety $\bar{x}$ in the negligence regime if

$$
\Pi^{N L}\left(q^{N L}(\bar{x}), \bar{x}\right) \geq \Pi^{S L}\left(q^{S L}, x^{S L}\right) .
$$

\subsubsection{Product Safety Standard Independent of Output}

We denote condition (19) as the compliance constraint. Facing the due level of product safety $\bar{x}$, the firm optimally chooses output $q^{N L}(\bar{x})=\arg \max _{q} \Pi^{N L}(q, \bar{x})$. As long as the quantity stays below the (conditional) social optimum, both changes (the increase in safety and quality) are welfare-improving. When imposing a fixed standard, the social planner can choose the product safety to maximize welfare subject to the compliance constraint and anticipate the monopolist's optimal quantity choice given the safety standard. This output is depicted as $q^{N L}(x ; 1 / 4)$ in Fig. 2 (which assumes $\theta=2, \alpha=1 / 4$ and $\beta=3 / 4>\hat{\beta}=1 / 2$ ). The figure illustrates that safety standards $\bar{x}$ exist (e.g., $\bar{x}=x^{S L}$ ) for this parameter constellation such that a negligence regime using this due product safety level as the standard yields higher welfare than the regimes with either No Liability or Strict Liability. ${ }^{8}$

According to Proposition 1(iii), if $\beta>\hat{\beta}(\alpha)$, No Liability can induce higher welfare than Strict Liability. While the firm's product safety under No Liability is clearly socially suboptimal given the quantity produced, the actual quantity can be too high or too low. It is too low if the quantity distortion due to the extraction of consumer surplus is a larger

${ }^{8}$ We explain the parameter constellation and provide a detailed description of the figure in Appendix C. 
problem than that due to the uncompensated harm, that is, if $b$ is sufficiently high. ${ }^{9}$ In this case, a marginal increase in the level of product safety-induced by an appropriately chosen standard-and the firm's associated response with higher output, is unambiguously welfare-enhancing. Thus:

Proposition 2 If $\beta>\hat{\beta}(\alpha)$ and $b$ is sufficiently high, safety standards $\bar{x}$ exist such that a negligence regime with a safety standard $\bar{x}$ yields higher welfare than No Liability and Strict Liability.

Note that the condition $\beta>\hat{\beta}(\alpha)$ is a necessary condition for a negligence regime to be welfare superior to the alternative regimes of No Liability or Strict Liability, while the condition on $b$ formulated in Proposition 2 (and explained in Appendix D) is sufficient but not necessary.

\subsubsection{Product Safety Standard as a Function of Output}

If we allow the standard of care to be a function of output, the social planner's problem is relaxed, as she is no longer limited to the set of points on the firm's best-response function $q^{N L}(\bar{x})$. Instead, she can deter a range of output choices by, for example, associating higher product safety standards with them. Therewith, she can induce her favorite $\left(q^{*}, x^{*}\right)$ out of those that satisfy the compliance constraint (19). Specifically, she can choose any point in Fig. 2 in the area surrounded by the dashed graph representing the firm's isoprofit-curve at the profit level obtained at $\left(q^{S L}, x^{S L}\right)$.

Fig. 2 Welfare isoquant for outcome under Strict Liability $\left(W\left(q^{S L}, x^{S L}\right)\right)$, output under No Liability as a function of safety $\left(q^{N L}(x ; 1 / 4)\right)$, isoprofitcurve under No Liability for outcome under Strict Liability $\left(\Pi^{N L}\left(q^{S L}, x^{S L}\right)\right) ; \alpha=1 / 4$, $\beta=3 / 4$

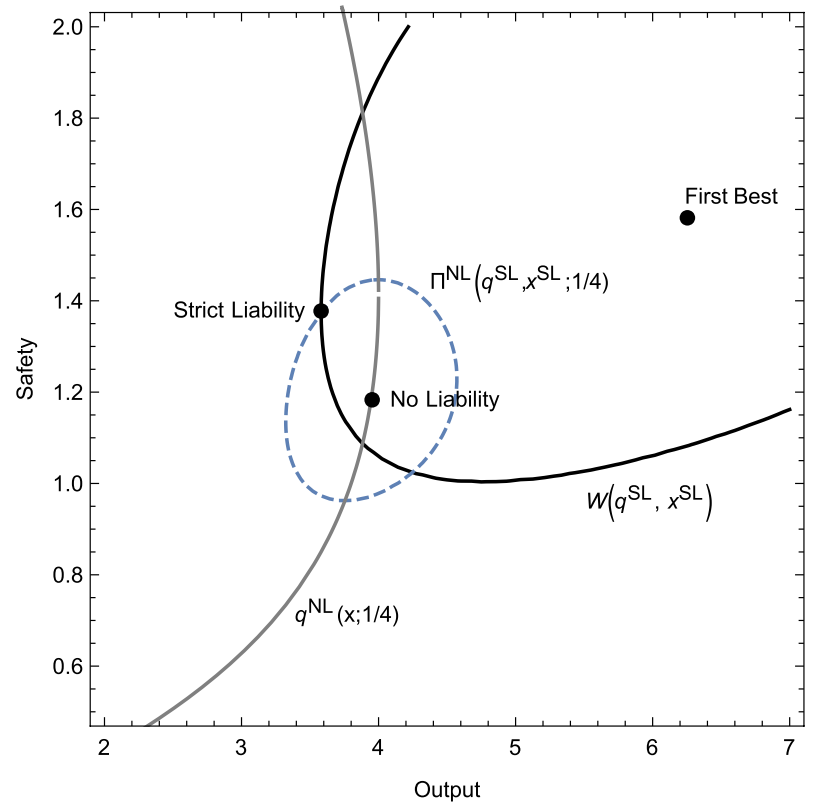

$\overline{9}$ See Appendix D for more details. 
As can be seen in the figure, in order to effectively guide the firm's choice towards the desired outcome, the due level of product safety may be non-monotonic in quantity. It is apparent that with full flexibility to choose such a function, the social planner can always improve welfare with an appropriately designed negligence regime if $\beta>\hat{\beta}(\alpha)$.

\subsection{Extensions}

In this section, we very briefly discuss two possible extensions. In the first, we explore the outcomes attainable when liability rules can be domain-specific, with liability in the domain of consumer harm being different from that in the domain of environmental harm. Next, we refer to regulation as another important policy instrument in the context of external effects.

\subsubsection{Differentiated Liability}

In our analysis, the liability regime considered was independent of the domain; that is, a firm subject to Strict Liability was made to provide full compensation for both consumer and environmental harm. However, differentiating the liability rule according to the kind of harm seems possible. To represent this possibility in a flexible way, imagine that the firm is held liable for a share $\delta_{\alpha}$ of the consumer's harm and a share $\delta_{\beta}$ of the environmental harm. This includes the extreme cases considered in Sects 3.1 and 3.2, namely No Liability when $\delta_{\alpha}=\delta_{\beta}=0$ and Strict Liability when $\delta_{\alpha}=\delta_{\beta}=1$. In addition, it captures the case of partial compensations for either kind of harm.

The policymaker has two policy targets, the level of output and the level of product safety. With differentiated liability, the policymaker has two instruments to design the liability regime and can ensure welfare levels (weakly) higher than those with undifferentiated liability. However, the two instruments are insufficient to induce the first-best outcome. Consider the case in which the firm is strictly liable for the full harm in both domains so that $\delta_{\alpha}=\delta_{\beta}=1$. Our analysis above clearly explained that, in this circumstance, the level of product safety is socially optimal conditional on the level of output and that the level of output is inefficiently low. When we lower the level of compensation for consumer harm (i.e., $\delta_{\alpha}$ ) and thereby move towards No Liability for consumer harm, we obtain that the consumers' concern for marginal harm, which is greater than average harm, would induce not only excessive product safety but also an even further decrease in the level of output. In contrast, when we reduce the level of compensation for environmental harm, $\delta_{\beta}$, we induce inefficiently low product safety but encourage greater output. This finding suggests that a combination of $\delta_{\alpha}=1>\delta_{\beta}$ can strike a good balance between the objectives in terms of output and product safety.

\subsubsection{Product Approval by a Regulator}

In order to complement our analysis, we point out the impact of a regulatory standard of product safety in the context of our model framework for the case $\beta>\hat{\beta}(\alpha)$.

Suppose that the firm's product is subject to approval by a regulator who is free to choose a minimum product safety standard $x$. In that case, such a regulator can potentially achieve an even better outcome than a negligence regime with an appropriately chosen due level of product safety. This finding is obtained because such a regulator's optimization problem is less constrained than that of a social planner using Negligence. While the 
compliance constraint deters the firm from opting into Strict Liability (and earning optimized monopoly profits in this regime) by not complying with the due level of product safety, the regulator must only respect a constraint that gives rise to non-negative profits. Thus, the reachable outcomes in a negligence regime with an output-independent due level of safety $\bar{x}$ are a subset of those that are reachable by imposing a minimum product safety standard $\underline{x}$ and No Liability. In this setting, if $\underline{x}$ is chosen optimally, there is no room for a welfare improvement by imposing a negligence regime with a fixed due care level $\bar{x}$.

As the negligence regime with a fixed product safety standard can outperform Strict Liability, this potential preference for regulation over Negligence implies that regulation is more desirable than Strict Liability. However, the arguments in this section must be interpreted cautiously as it considers frictionless regulation. Problems usually associated with regulation include monitoring or an insufficient adjustment of the regulation to the firm's circumstances (e.g., Shavell 1984).

Perhaps surprisingly, regulation of the kind described above need not be better than liability law. If the due level of safety can be imposed as a function of the quantity (but the regulatory standard cannot), holding the firm liable in such a negligence regime may still increase welfare, as it allows points in the set described by the compliance constraint that are not on the firm's response function $q^{N L}$.

\section{Conclusion}

Firm activity often creates expected harm for both consumers and third parties or the environment. Nevertheless, this fact has been neglected in the literature about firm liability. This paper shows that the relative performance of liability rules can drastically change when third parties/the environment incur expected harm simultaneously to consumers. In contrast to the findings by Daughety and Reinganum (2014) about the consumer-only scenario, we establish circumstances in which No Liability and Negligence can outperform Strict Liability. This possibility emerges only when third-party harm is sufficiently important as a harm category relative to consumer harm.

In terms of policy implications, our analysis shows which of the three regimes is most desirable for any specific context. In our framework, the relative importance of losses incurred by consumers when compared to environmental harm is critical. When environmental harm is relatively important (in the sense of $\beta>\hat{\beta}$ ), No Liability can dominate Strict Liability. Then, if an assessment about the relative importance can be made at the industry level, for example, our paper offers clear policy lessons. Additionally, we find that Negligence may actually be the preferred liability regime, but it depends very much on how the standard of conduct is defined.

Our analysis is kept very simple. For example, we assume linear demand, a convex power function where consumer harm and third-party harm have the same functional form and simply add up, and a monopolistic firm. Nevertheless, we believe that the basic insight that the simultaneity of consumer and third-party harm should be an important factor when policymakers choose a liability rule is relevant and opens avenues for future research.

\section{Appendix A: Welfare Maximization}

We specify welfare as 


$$
W=\left(a-\frac{b}{2} q-c(x)\right) q-\gamma h(x) q^{\theta}
$$

and obtain the first-order conditions

$$
\begin{gathered}
W_{q}(q, x)=a-b q-c(x)-\gamma \theta h(x) q^{\theta-1}=0 \\
W_{x}(q, x)=-c^{\prime}(x) q-\gamma h^{\prime}(x) q^{\theta}=0 .
\end{gathered}
$$

From these conditions, we obtain

$$
\begin{gathered}
W_{q q}(q, x)=-b-\gamma\left(\theta^{2}-\theta\right) h(x) q^{\theta-2}<0 \\
W_{q x}(q, x)=-c^{\prime}(x)-\gamma \theta h^{\prime}(x) q^{\theta-1} \\
W_{x x}(q, x)=-c^{\prime \prime}(x) q-\gamma h^{\prime \prime}(x) q^{\theta}<0 .
\end{gathered}
$$

At the welfare-maximizing combination of safety and output, the social planner fulfills condition (22). Using a reformulation of this expression to restate the cross-partial derivative as

$$
W_{q x}(q, x)=-\gamma(\theta-1) h^{\prime}(x) q^{\theta-1}>0
$$

we find that

$$
D=W_{q q} W_{x x}-\left(W_{q x}\right)^{2}>0
$$

because

$$
\gamma^{2} q^{2(\theta-1)}\left[\left(\theta^{2}-\theta\right) h h^{\prime \prime}-(\theta-1)^{2}\left(h^{\prime}\right)^{2}\right]>0
$$

by $\theta>1$ and the assumption that $H$ is strictly convex.

\section{Appendix B: Comparative-Statics Results and Proof of Lemma 1}

Starting from the profit equation specified in equation (10) in the main document,

$$
\Pi(q, x)=(a-b q-c(x)) q-\alpha \kappa h(x) q^{\theta},
$$

we obtain the first-order conditions in (11) and (12),

$$
\begin{aligned}
& \Pi_{q}(q, x)=a-2 b q-c(x)-\alpha \kappa \theta h(x) q^{\theta-1}=0 \\
& \Pi_{x}(q, x)=-c^{\prime}(x) q-\alpha \kappa h^{\prime}(x) q^{\theta}=0 .
\end{aligned}
$$

From these conditions, we obtain

$$
\Pi_{q q}(q, x)=-2 b-\alpha \kappa\left(\theta^{2}-\theta\right) h(x) q^{\theta-2}<0
$$




$$
\begin{gathered}
\Pi_{q x}(q, x)=-c^{\prime}(x)-\alpha \kappa \theta h^{\prime}(x) q^{\theta-1} \\
\Pi_{x x}(q, x)=-c^{\prime \prime}(x) q-\alpha \kappa h^{\prime \prime}(x) q^{\theta}<0 .
\end{gathered}
$$

At the profit-maximizing combination of safety and output, the firm fulfills condition (12). Using a reformulation of this expression to restate the cross-partial derivative as

$$
\Pi_{q x}(q, x)=-\alpha \kappa(\theta-1) h^{\prime}(x) q^{\theta-1}>0,
$$

we find that

$$
G=\Pi_{q q} \Pi_{x x}-\left(\Pi_{q x}\right)^{2}>0
$$

because

$$
\alpha^{2} \kappa^{2} q^{2(\theta-1)}\left[\left(\theta^{2}-\theta\right) h h^{\prime \prime}-(\theta-1)^{2}\left(h^{\prime}\right)^{2}\right]>0
$$

by $\theta>1$ and the assumption that $H$ is strictly convex.

The comparative-static properties of the firm's problem follow from

$$
\left(\begin{array}{cc}
\Pi_{q q} & \Pi_{q x} \\
\Pi_{x q} & \Pi_{x x}
\end{array}\right)\left(\begin{array}{c}
d q \\
d x
\end{array}\right)=\left(\begin{array}{c}
-\Pi_{q \kappa} \\
-\Pi_{x \kappa}
\end{array}\right) d \kappa
$$

where

$$
\begin{gathered}
\Pi_{q \kappa}=-\alpha \theta h(x) q^{\theta-1}<0 \\
\Pi_{x \kappa}=-\alpha h^{\prime}(x) q^{\theta}>0 .
\end{gathered}
$$

This implies that the output and safety levels change as follows with a change in $\kappa$ :

$$
\begin{gathered}
\frac{d q}{d \kappa}=\frac{\Pi_{q x} \Pi_{x \kappa}-\Pi_{q \kappa} \Pi_{x x}}{G}=\frac{\alpha^{2}\left(h^{\prime}\right)^{2} q^{2 \theta-1} \kappa(\theta-1)-\alpha \theta h q^{\theta-1}\left(c^{\prime \prime} q+\alpha \kappa h^{\prime \prime} q^{\theta}\right)}{G}<0 \\
\frac{d x}{d \kappa}=\frac{\Pi_{q x} \Pi_{q \kappa}-\Pi_{x \kappa} \Pi_{q q}}{G}=-\frac{\alpha h^{\prime} q^{\theta} 2 b}{G}>0
\end{gathered}
$$

where the sign in (36) stems from

$$
\alpha^{2} q^{2 \theta-1} \kappa \theta\left[\left(h^{\prime}\right)^{2}-h h^{\prime \prime}\right]<0
$$

as a result of the convexity of $H$.

The fact that the firm subjected to Strict Liability internalizes all social marginal effects when it comes to product safety means that $x^{S L}=x^{W}$ for all $\beta$. Considering output, the firm under Strict Liability internalizes the adequate marginal costs but inadequate marginal benefits such that $q^{S L}<q^{W}$ for all $\beta$. At $\beta=\hat{\beta}$, product safety and output levels are independent of whether Strict Liability or No Liability is used. As a result, the profit-maximizing conditional product safety under No Liability is short (in excess) of the socially optimal level when $\beta>(<) \hat{\beta}$. The consideration of a higher (lower) $\beta$ means (via a higher (lower) $\kappa^{S L}$ ) that output under Strict Liability decreases (increases) 
relative to the level obtained when $\beta=\hat{\beta}$, whereas the conditional output under No Liability is not affected (as $\kappa^{N L}$ is not varied) by the respective variation in $\beta$.

\section{Appendix C: More Explanations on Fig. 2}

Figure 2 shows the socially optimal combination of output and safety ("First Best") along with the firm's choices under Strict Liability ("Strict Liability"), and under No Liability ("No Liability") for the parameter constellation $a=10, b=1, c(x)=(1 / 2) x^{2}$, $h(x)=(1 / 2) x^{-2}, \theta=2, \alpha=1 / 4$ and $\beta=3 / 4>\hat{\beta}=1 / 2$. The u-shaped curve that runs through the point "Strict Liability", labelled $W\left(q^{S L}, x^{S L}\right)$, displays output-safety-combinations that yield the same level of welfare defined by the outcome attained under Strict Liability; all points to the north-east are socially preferred, including the output-safety combination induced by No Liability. The curve running through the point "No Liability", labeled $q^{N L}(x ; 1 / 4)$, is the firm's output response to a particular safety standard when she faces No Liability (but is forced to comply with the standard). Finally, the dashed ellipse surrounding the point "No Liability" and running through the point "Strict Liability", labeled $\Pi^{N L}\left(q^{S L}, x^{S L} ; 1 / 4\right)$, is an isoprofit curve of the firm. The firm obtains higher profits than her maximum profits under Strict Liability if she faces No Liability and chooses a point inside the ellipse. All points on the response function $q^{N L}(x)$ inside the ellipse satisfy the compliance constraint (19).

Consider a standard of due care $x=x^{S L}$ and its associated output in a negligence regime (i.e., the output level $q^{N L}\left(x^{S L}\right)$ on the firm's response function): This combination lies within the set of points that are preferred by the firm to the outcome under Strict Liability, and it lies within the set of points that are socially preferred to the outcome under Strict Liability (i.e., above the curve $W\left(q^{S L}, x^{S L}\right)$ ). Thus, allowing the firm to escape liability when providing safety level $x=x^{S L}$ makes society and the firm better off.

More generally, all the points in the intersection between $\Pi^{N L}\left(q^{S L}, x^{S L} ; 1 / 4\right)$ and $W\left(q^{S L}, x^{S L}\right)$ improve welfare when compared to the outcome that results when the firm is subject to Strict Liability. In a negligence regime with a due standard of care independent of output, these points on $q^{N L}(x ; 1 / 4)$ can be implemented with an appropriately chosen standard of care. If the standard is allowed to depend on the firm's output, all the points surrounded by the dashed line are implementable.

\section{Appendix D: Derivation of Critical Level of $b$ Used in Proposition 2}

The exact threshold follows from comparing the first-order conditions (2) and (5).

For a fixed standard of care $\bar{x}$, the first-order conditions demand

$$
q^{N L}(\bar{x})\left(2 b+\alpha \theta^{2} h(\bar{x}) q^{N L}(\bar{x})^{\theta-2}\right)=q^{W}(\bar{x})\left(b+(\alpha+\beta) \theta h(\bar{x}) q^{W}(\bar{x})^{\theta-2}\right) .
$$

Suppose $q^{N L}(\bar{x})>q^{W}(\bar{x})$. Then, the second factor on the left-hand side must be smaller than its counterpart on the right-hand side in order to satisfy the equation, which requires

$$
b<\theta h(x)\left((\alpha+\beta) q^{W}(\bar{x})^{\theta-2}-\alpha \theta q^{N L}(\bar{x})^{\theta-2} .\right.
$$

The inequality cannot be met if $b$ is too high. For $\beta$ close enough to $\hat{\beta}$, it would even require a negative $b$. In contrast, if $b$ is sufficiently high, the second factor on the left-hand side is 
larger than its counterpart on the right-hand side, so that $q^{N L}(\bar{x})<q^{W}(\bar{x})$ is necessary to satisfy the equation. For $\theta=2$, the (necessary and) sufficient condition for $q^{N L}(\bar{x})<q^{W}(\bar{x})$ simplifies to

$$
b>2(\beta-\alpha) h(\bar{x}) \text {. }
$$

Acknowledgements We gratefully acknowledge the very helpful comments and suggestions received from three anonymous reviewers on earlier versions of this manuscript. We are also thankful for the feedback provided at the IIPF 2020 and the Annual Meeting of the German Law \& Economics Association.

Funding Open Access funding enabled and organized by Projekt DEAL.

Open Access This article is licensed under a Creative Commons Attribution 4.0 International License, which permits use, sharing, adaptation, distribution and reproduction in any medium or format, as long as you give appropriate credit to the original author(s) and the source, provide a link to the Creative Commons licence, and indicate if changes were made. The images or other third party material in this article are included in the article's Creative Commons licence, unless indicated otherwise in a credit line to the material. If material is not included in the article's Creative Commons licence and your intended use is not permitted by statutory regulation or exceeds the permitted use, you will need to obtain permission directly from the copyright holder. To view a copy of this licence, visit http://creativecommons.org/licenses/by/4.0/.

\section{References}

Arlen J (2010) Contracting over liability: medical malpractice and the cost of choice. Univ Pa Law Rev 159:957-1023

Boyer M, Laffont JJ (1997) Environmental risks and bank liability. Eur Econ Rev 41:1427-1459

Charreire M, Langlais E (2021) Should environment be a concern for competition policy when firms face environmental liability? Int Rev Law Econ 67:105990

Chen Y, Hua X (2017) Competition, product safety, and product liability. J Law Econ Organ 33:237-267

Choi AH, Spier KE (2014) Should consumers be permitted to waive products liability? Product safety, private contracts, and adverse selection. J Law Econ Organ 30:734-766

Daughety AF, Reinganum JF (1995) Product safety: liability, R\&D, and signaling. Am Econ Rev $85: 1187-1206$

Daughety AF, Reinganum JF (2006) Markets, torts, and social inefficiency. Rand J Econ 37:300-323

Daughety AF, Reinganum JF (2013a) Cumulative harm, products liability, and bilateral care. Am Law Econ Rev 15:409-442

Daughety A, Reinganum J (2013b) Economic analysis of products liability: theory. In: Arlen JH (ed) Research handbook on the economics of torts. Edward Elgar, London

Daughety AF, Reinganum JF (2014) Cumulative harm and resilient liability rules for product markets. J Law Econ Organ 30:371-400

Dias M, Rocha R, Soares RR (2019) Glyphosate use in agriculture and birth outcomes of surrounding populations. IZA Discussion Paper No. 12164

Endres A (2011) Environmental economics: theory and policy. Cambridge University Press, Cambridge

Endres A, Friehe T (2011) Incentives to diffuse advanced abatement technology under environmental liability law. J Environ Econ Manag 62:30-40

Endres A, Friehe T (2015) The compensation regime in liability law: incentives to curb environmental harm, ex ante and ex post. Environ Resour Econ 62:105-123

Endres A, Bertram R, Rundshagen B (2007) Environmental liability law and induced technical change-the role of discounting. Environ Resour Econ 36:341-366

Evans MF, Gilpatric SM (2017) Abatement, care, and compliance by firms in financial distress. Environ Resour Econ 66:765-794

Friehe T, Langlais E (2017) Prevention and cleanup of dynamic harm under environmental liability. J Environ Econ Manag 83:107-120

Friehe T, Langlais E, Schulte E (2018) On consumer preferences for (partial) products liability. Econ Lett 173:128-130

Geistfeld M (2009) Products liability. In: Faure M (ed) Tort law and economics. Edward Elgar, London 
Hansen RG, Thomas RS (1999) The efficiency of sharing liability for hazardous waste: effects of uncertainty over damages. Int Rev Law Econ 19:135-157

Hay B, Spier KE (2005) Manufacturer liability for harms caused by consumers to others. Am Econ Rev 95:1700-1711

Heberer T (2002) Occurrence, fate, and removal of pharmaceutical residues in the acquatic environment: a review of recent research data. Toxicol Lett 131:5-17

Li WC (2014) Occurrence, sources, and fate of pharmaceuticals in acquatic environment and soil. Environ Pollut 187:193-201

Marino A (1988) Monopoly, liability and regulation. South Econ J 54:913-927

Martinez JL (2009) Environmental pollution by antibiotics and by antibiotic resistance determinants. Environ Pollut 157:2893-2902

Mäler KG, Xepapadeas A, de Zeeuw A (2003) The economics of shallow lakes. Environ Resour Econ 26:603-624

Prata JC, da Costa JP, Lopes I, Duarte AC, Rocha-Santos T (2020) Environmental exposure to microplastics: An overview on possible human health effects. Sci Total Environ 702:134455

Sanchis J, Kantiani L, Llorca M, Rubio F, Ginebreda A, Garrido T, Farre M (2012) Determination of glyphosate in groundwater samples using an ultrasensitive immunoassay and confirmation by on-line solid-phase extraction followed by liquid chromatography coupled to tandem mass spectrometry. Anal Bioanal Chem 402:2335-2345

Shavell S (1980) Strict liability versus negligence. J Legal Stud 19:1-25

Shavell S (1984) A model of the optimal use of liability and safety regulation. Rand J Econ 15:271-280

Shavell S (1987) Economic analysis of accident law. Harvard University Press, Cambridge

Shavell S (2007) Liability for accidents. In: Polinsky AM, Shavell S (eds) Handbook of law and economics 1. Elsevier, Amsterdam, pp 139-182

Van Egteren H, Smith RT (2002) Environmental regulations under simple negligence or strict liability. Environ Resour Econ 21:369-396

Watabe A (1999) The effect of liability-sharing rules in delegating hazardous activities. Int Rev Law Econ 19:349-368

Wickelgren A (2006) The inefficiency of contractually-based liability with rational consumers. J Law Econ Organ 22:168-183

Publisher's Note Springer Nature remains neutral with regard to jurisdictional claims in published maps and institutional affiliations. 